\title{
Retrospective observational study of performance in outcome of emergency appendicectomy
}

\author{
Gupta S.S ${ }^{1}$, Pal B ${ }^{2}$, Jha H.N ${ }^{3}$
}

${ }^{1}$ Dr. Siladri Sen Gupta, Associate Professor \& Head, unit II, ${ }^{2}$ Dr Banyeswar Pal, Assistant Professor, ${ }^{3}$ Dr Hem Narayan Jha, Junior Resident; all authors are affiliated with Department of General Surgery, ESIC-PGIMSR, ESIC Medical College And ESIC Hospital \& DOC (EZ) Zoka Diamond Harbour Road, Kolkata, West Bengal, India

Address for correspondence: Dr. Siladri Sen Gupta, Email: siladrisen2@gmail.com

\begin{abstract}
Objective: The present study is aimed to investigate variations in outcome of Emergency Appendectomy being conducted in Surgery Unit- II at ESIC Medical College, Joka, Diamond Harbour Road, Kolkata, West Bengal. The main outcome interest was the normal Histopathology rate, secondary outcomes and thirty (30) days adverse events rate with varied parameters like different timings of operation, presence or absence of consultant etc. Method: The study was performed in Surgery UNIT II in ESIC Medical College, Joka, Kolkata, and West Bengal. The trainee level Investigator was responsible for identifying patients, entering DATA in the prespecified database and ensuing completeness of data. Patients undergoing appendectomy for suspected Acute Appendicitis between Aug 2015 to Aug 2016 inclusive of all age \& sex are included in this study. The study was approved by the Institutional ethical committee. The post operative complications were followed for 30 days after surgical appendectomy during day time, evening hours and night time and compared in terms of percentage of evidence. Results: A total number of fifty (50) Emergency appedidectomy cases were studied by open surgery. Histologically Normal appendix was removed in 10 numbers of cases i.e. 20\%.It was observed that the outcome percentage of daytime operation with requisite duration and by specialist consultant is far better than that of night time or evening time operation by senior trainee. It was also observed that adverse effects after 30days post operative period were significantly reduced in case of day time operation. Conclusions: This study reveals the wide variations in practice patterns and outcome which should be addressed to improve performance.. The surgical procedure done in day time by expertise consultant can effectively reduce the adverse post operative complications.
\end{abstract}

Key words: Emergency appendectomy, post appendectomy complications, Adverse affects of appendectomy

\section{Introduction}

Emergency appendectomy is the most common performed Acute General Surgical Operations [1]. Differing Hospital policies, financial constraints, clinical burdens and a conflicting evidence base may result in variation in the provision and outcome of appendectomy [2].

Manuscript Received: $04^{\text {th }}$ September 2016

Reviewed: $12^{\text {th }}$ September 2016

Author Corrected: $20^{\text {th }}$ September 2016

Accepted for Publication: 30 $0^{\text {th }}$ September 2016
Mortality following appendectomy is low and is unsuitable as a quality marker. Several controversies remain surrounding the management and outcome of appendicitis including the best investigation for diagnosis, optimal surgical approach and strategies to limit adverse post-operative events [3-5]. The aim of the present study is to identify retrospectively and investigate the variations in the provision and outcome of Emergency Appendectomy. While taking into account the various 
measures and working mode of performing acute emergency appendectomy the study aims at measures which can be modified to achieve more favourable result.

\section{Method}

The study was performed according to a prespecified protocol which were tested and modified in Surgery Unit II in Esic Medical College, Joka, Kolkata, West Bengal. The trainee level Investigator was responsible for identifying patients, entering DATA in the prespecified database and ensuing completeness of data. Patients undergoing appendectomy for suspected Acute Appendicitis between Aug 2015 to Aug 2016 inclusive of all age $\&$ sex are included in this study.

Patients in which surgical appendectomy was planned electively or was a part of another procedure (such as a part of elective Right Hemi colonectomy) were excluded from this study design. The study was approved by the Institutional ethical committee.

Outcome Measures: The main outcome of interest was the histopathologic normal appendectomy rate. Other adverse events were wound infection, intra-abdominal abscess, readmission, unscheduled postoperative ultrasound scan, or computerised tomography and further radiological or surgical intervention within 30 days. Wound infection was defined according to the definition provided by the Centre for disease control [6]. The detail outcome measure for the operation is tabulated along with the result in table 1.

Data Collection: Data domains were collected relating to the patient, surgeon, operation, hospital, operative method and post-operative period. The details of the operative protocol is given in table 1 along with the results.

\section{Results}

Normal Appendix was removed in 10 patients which was significantly higher in females than in males and lower in those aged between $16-50$ yrs. or less than 16 yrs.

Table-1: Experimental protocol along with the outcome in terms of percentage

\begin{tabular}{|c|c|c|c|}
\hline Parameters & Number & Timing & Percentage \\
\hline 1 No of cases & 50 ( Fifty) & & \\
\hline 2 Alvardo scoring & $\begin{array}{c}\text { I - II }-20 \\
\text { III - IV }-30\end{array}$ & & $\begin{array}{l}40 \% \\
60 \%\end{array}$ \\
\hline 3 Age in yrs & $8-65$ yrs & & \\
\hline $4 \mathrm{Sex}$ & $\begin{array}{c}\text { Male }-25 \\
\text { Female }-25\end{array}$ & & $\begin{array}{l}50 \% \\
50 \%\end{array}$ \\
\hline 5Pre-operative imaging & $\begin{array}{c}\text { X-Ray }-50 \\
\text { USG }-50 \\
\text { CT }- \text { Nil }\end{array}$ & & $\begin{array}{c}100 \% \\
100 \% \\
\text { NA }\end{array}$ \\
\hline 6 Timing of Operations & $\begin{array}{l}25 \\
15 \\
10\end{array}$ & $\begin{array}{l}\text { Day timing }-8.00-1800 \\
\text { Evening Timing - } 1800-2200 \\
\text { Night Timing - } 2200-8.00\end{array}$ & $\begin{array}{l}50 \% \\
30 \% \\
20 \%\end{array}$ \\
\hline 7 Earlier Antibiotics & $\begin{array}{l}50 \\
50\end{array}$ & $\begin{array}{l}\text { Pre-operative/ Induction } \\
\text { Intraoperative / Postoperative }\end{array}$ & $\begin{array}{l}100 \% \\
100 \%\end{array}$ \\
\hline 8 Operative Method -- & 50 & Open appendectomy & $100 \%$ \\
\hline 9. Operating Surgeon --- & $\begin{array}{l}30 \\
20 \\
\text { Nil }\end{array}$ & $\begin{array}{l}\text { Consultant } \\
\text { Senior Trainee } \\
\text { Junior Trainee }\end{array}$ & $\begin{array}{l}60 \% \\
40 \% \\
\text { NA }\end{array}$ \\
\hline
\end{tabular}


Original Article

\begin{tabular}{|l|c|l|c|}
\hline Parameters & Number & Timing & Percentage \\
\hline 10 Consultant Surgeon in theatre & 30 & Yes & $60 \%$ \\
& 20 & No & $40 \%$ \\
\hline 11. Duration of Surgery & 40 & $<60$ mins & $80 \%$ \\
& 20 & $>60$ mins & $20 \%$ \\
\hline 12. Abdominal washout - & 40 & No & $20 \%$ \\
\hline 13. Drain & 10 & Yes & $80 \%$ \\
& 10 & Yes & $20 \%$ \\
\hline 14. Skin Closure & 40 & No & $80 \%$ \\
& 40 & Subcutaneous Suture & $20 \%$ \\
\hline 15. Histopathology & 10 & Interrupted suture & $20 \%$ \\
& 10 & Normal appendix & $30 \%$ \\
\hline 16. 30-Day adverse events & 15 & Simple appendicitis & $50 \%$ \\
\hline 17. Post - operative Imaging & 25 & Complicated appendicitis & $16 \%$ \\
\hline
\end{tabular}

The Table-1 shows that the outcome percentage of daytime operation with requisite duration and by specialist consultant is far better than that of night time or evening time operation by senior trainee. As evident from the fact that the wound infection is observed only in $16 \%$ cases in case of daytime operation with presence of senior consultant and abscess formation is reduced to only $4 \%$ cases.

It was also observed that adverse effects after 30 days post operative period were experienced by only 10 patients ( 10 of 50 ). Hospital Characteristics is also significantly associated with a reduced rate of adverse events.

\section{Discussion}

Daytime surgery, higher volume, consultant presence in theatre was organizational factors associated with improved provision and outcome from emergency appendectomy in the present study. These factors could be addressed to ensure high quality delivery of acute surgical care with appendectomy potentially acting as a quality marker of this care.

The present study shows a clear association between higher volume, consultant presence and day time surgery thereby showing a reduction in 30 day morbidity rates.

Daytime surgery further reduced normal appendectomy rate and there is increasing evidence that short delays to allow operation within normal hours does not increase the rate of perforation $[7,8]$ but the impact of surgical site infection (SSI) requires further research.

As it is found that a short delay will improve the outcome by performing during day time in presence of consultants without causing any morbidity on patients.

Improvements to standardize variation could be drawn from the markers of provision identified including imaging, Laparoscopy, and Consultant supervision rates. Increased use of laparoscopy may reliably reduce normal appendectomyrate [6], although this analysis was beyond the scope of this study. Although a high rate of CT use was not associated with a reduction in normal 
appendectomy rate, the overall use of CT was low [9] and non-randomized.

The low rate suggests that there may be underutilization especially in comparison with the higher Imaging rates used elsewhere. In the USA pre-operative imaging rate of 91\% (predominantly CT) with associated normal appendectomy rate 5.6\% have been reported [9].

Both randomized and population based studies (cite reference) also support the effectiveness of CT in reducing the Normal appendectomy rates.

The strength of the present study is the generalized ability and the detail DATA collection. This study used the original pathology report as the marker of final histopathology, although differing criteria between pathologists regarding the definition of appendicitis is controversial $[4,10]$.

Although the SSI rate in this study (3-4 \%) was in keeping with that from randomized trials and meta-analysis these rates still may significantly underestimate the true incidence. When properly defined an assessed the rate following abdominal operations may be as high as $20 \%$.

The limitation of using this composite end point includes its inability to identify specific benefits or risks for a particular intervention.

The association of abdominal washout, drains and various skin closure techniques was variable and often high with little robust evidence to guide their practice. Their association within this non-randomized study is more likely as marker of severity than as causative factors.

The above observation concludes that if Emergency operations are performed in Daytime and in presence of Consultants than the rate of associated complications are low.

Conflict of interest: None declared.

Funding: Nil, Permission from IRB: Yes

\section{References}

1. Hospital Episode statistics. Admitted patients care England 2011-2012.Total procedure and Interventions.

2. Fine LG, Keogh BE, Cretin S et al.,Cardiac surgery Experience:How to evaluate and improve the quality and credibility of an outcome database-Validation and feedback studyon UK,BMJ,326,25-28.

3. Alder AC, Fomby TB, Woodward WA, Haley RW, Sarosi G, Livingston EH. Association of viral infection and appendicitis.Arch Surg. 2010 Jan;145(1):6371. doi: 10.1001/archsurg.2009.250.

4. Ignacio RC, Burke R, Spencer D, Bissell C, Dorsainvil C, Lucha PA. Laparoscopic versus open appendectomy: what is the real difference? Results of a prospective randomized double-blinded trial. Surg Endosc. 2004 Feb;18(2):334-7. Epub 2003 Dec 29.

5. Patterson HM, QadanM,delaca SM, Nixon SJ,Patterson- BrownS, Changing trends in surgery for acute appendicitis Br J Surg,2008,95:303-308.

6. Güller U, Rosella L, McCall J, Brügger LE, Candinas

D. Negative appendicectomy and perforation rates in patients undergoing laparoscopic surgery for suspected appendicitis. Br J Surg. 2011 Apr;98(4):589-95. doi: 10.1002/bjs.7395. Epub 2011 Jan 24.

7. Teixeira PG, Sivrikoz E, Inaba K, Talving P, Lam L, Demetriades D. Appendectomy timing: waiting until the next morning increases the risk of surgical site infections. Ann Surg. 2012 Sep;256(3):538-43. doi: 10.1097/SLA.0b013e318265ea13.

8. Cuscheri J, Florence M,Flum DR . JurkovichGJ, LInp,SrelleSR et al,Negativeappendidectomy and Imaging accuracy in the Washington State surgical care and outcome assessment programme.Ann. surg.,2008, 248:557-558. 
9. Lee CC, Golub R, Singer AJ, Cantu R Jr, Levinson H.

Routine versus selective abdominal computed tomography scan in the evaluation of right lower quadrant pain: a randomized controlled trial. Acad Emerg Med. 2007 Feb;14(2):117-22. Epub 2006 Dec 27.
10. Sicard N, Toussignant P, Pineault R, Dube S, Non patient factors related to rates of ruptured appendicitis, $\mathrm{Br}$. J Surg,2007,94,214-21.

\section{How to cite this article?}

Gupta S.S, Pal B, Jha H.N. Retrospective observational study of performance in outcome of emergency appendicectomy. Int J surg Orthopedics 2016;2(3):37-41.doi: 10.17511/ijoso.2016.i03.03 